\title{
IFHUt:
}

\section{ANOTACIONES MANUSCRITAS EN BIBLIOTECAS DE AUTOR. PROPUESTA DE ETIQUETADO Y DE PUBLICACIÓN DIGITAL}

\section{MARGINALIA IN AUTHOR LIBRARIES. PROPOSAL OF ENCODING AND DIGITAL PUBLICATION}

José Luis Losada Palenzuela

Universidad de Wroclaw

jose-luis.losada@uwr.edu.pl

\begin{abstract}
Resumen
En los libros que pertenecieron a Arthur Schopenhauer -entre ellos, sus libros españoles-, se encuentran anotaciones manuscritas, marcas de lectura, glosas y dibujos. Nos referimos a un tipo específico de anotación conocida en inglés como author's marginalia. Muy pocos de estos se publican debido a la complejidad de la edición; incluso en el creciente mundo digital suponen un reto, pues casi siempre van unidos al contexto en el que surgen, la materialidad del libro. Este artículo ofrece una propuesta general que busca justificar su utilidad, los criterios de etiquetado elegidos (XML-TEI) y el entorno de publicación (Drupal implementado con el módulo TEICHI).
\end{abstract}

Palabras clave: XML-TEI. Anotaciones manuscritas. Schopenhauer. Drupal. TEICHI.

\begin{abstract}
Among the books that once belonged to Arthur Schopenhauer -including his Spanish books-, we found handwritten notes, reading marks, annotations and drawings. We refer to a specific type of annotation within an author's personal library: the author's marginalia. Very few are edited, due to the complexity of the editions; even for the new digital approach they present a
\end{abstract}


challenge, because they are frequently linked to the context in which they appear, the materiality of the book. This paper presents a general proposal which aims to show the utility of such digital edition, the criteria used for the encoding (XML-TEI) and the framework for the publication (Drupal implemented with the module TEICHI).

Keywords: XML-TEI. Marginalia. Schopenhauer. Drupal. TEICHI.

\title{
1. INTRODUCCIÓN
}

\begin{abstract}
Muchos borrones toparás, si lo quisieres acertar: haz de todos uno. Para su enmienda te dexo las márgenes desembaraçadas, que suelo yo dezir que se introduxeron para que el sabio letor las vaya llenando de lo que olvidó o no supo el autor, para que corrija él lo que erró éste (Gracián, 1647: 14).
\end{abstract}

Las anotaciones manuscritas en las bibliotecas personales de escritores, científicos o filósofos suelen estar al margen de los estudios textuales. Con marcas autógrafas en libros impresos, nos referimos a un tipo específico de anotación presente en los textos usados para el estudio, la lectura, la creación poética o filosófica de sus propietarios, que solo recientemente han empezado a ser analizados desde perspectivas modernas. Pocos se difunden, debido a la complejidad de su edición o diseño editorial (también en un entorno digital). La mera digitalización del documento, aunque facilita su localización, se queda corta por la falta de contextualización.

En este artículo ponemos como ejemplo la biblioteca personal de Arthur Schopenhauer. La afición del filósofo alemán por la lectura de los clásicos españoles (Cervantes, Calderón, Gracián) no solo encuentra reflejo en su obra filosófica, sino también en su labor como traductor al alemán del Oráculo manual y arte de prudencia de Baltasar Gracián (Losada Palenzuela, 2011). En algunos de los ejemplares que le pertenecieron, entre ellos, sus libros españoles, se encuentran anotaciones manuscritas, marcas de lectura y glosas (Hübscher, 1968).

Quisiéramos justificar, a la luz del proyecto de edición digital de estas anotaciones manuscritas, tres aspectos: la utilidad de su edición, la selección de los criterios de codificación (XML-TEI) y el entorno de publicación elegido (Drupal con el módulo TEICHI) ${ }^{1}$.

\footnotetext{
${ }^{1}$ Accesible desde http://schopenhauer.uni.wroc.pl/
} 


\section{MARGINALIA DE AUTOR}

Schopenhauer no era un bibliófilo ni tenía una amplia biblioteca (a su muerte esta contaba con unos 3.000 volúmenes) si la comparamos con otras bibliotecas privadas de pensadores coetáneos, como la biblioteca del escritor romántico y traductor del Quijote, Ludwig Tieck (en el momento de su salida a subasta, aún en vida, contaba con 16000 volúmenes). Los autores compartían, eso sí, la necesidad del acceso directo a las fuentes primarias y de poseer sus propios libros para la anotación y el estudio (Hölter, 2011: 315). Una primera recopilación documental de la biblioteca de Schopenhauer se la debemos a Arthur Hübscher, estudioso y editor de su obra. Hübscher fue el primero en señalar muchos de los pasajes con marcas y anotaciones reconociendo que la biblioteca del filósofo es un buen ejemplo del uso de libros como archivo de las propias ideas (Hübscher, 1968).

Una treintena de títulos españoles, solo en parte digitalizados, se conservan en la actualidad en el Schopenhauer-Archiv con sede en la Biblioteca Universitaria de Fráncfort del Meno $^{2}$. Algunos recogen anotaciones manuscritas y marcas de lectura, donde la mayoría son subrayados, líneas verticales en los márgenes, referencias cruzadas o breves glosas. Me refiero a un tipo específico de anotación dentro de la biblioteca personal de un autor que en el ámbito anglosajón suele denominarse author's marginalia (Jackson, 2001; Jackson, 2005) y que recientemente se está empezando a investigar sistemáticamente para desvelar el "potential value of reader's notes for historical studies of reception and reader response" (Jackson, 2001: 6). No incluyó manifestaciones textuales similares con larga tradición en diferentes campos científicos como las marcas anónimas en manuscritos medievales, scholia o glosas clásicas (para los estudios filológicos); marginalia scaenica (estudios teatrales); libros sujetos a censura; notas de un escritor como editor de su propia obra (crítica genética), sino de marcas y anotaciones manuscritas (marginalia) en las bibliotecas personales de modernos pensadores y escritores. Todas ellas comparten ciertamente una perspectiva común: muestran las huellas que los procesos íntimos de lectura, dejan en un texto.

Este corpus de anotaciones y marcas en los libros a veces se recogen en el aparato de una edición crítica o se incluyen en los estudios clásicos de recepción, pero suelen ser normalmente excluidas en los trabajos de crítica textual. Su brevedad, su carácter provisional, preliminar o inacabado cargan de prejuicios su edición y las relegan a una especie de tierra de nadie, aunque esto ya esté cambiando como escriben Van Mierlo y Van Hulle (2004: 5-6): "[w]hereas textual criticism and scholarly editing used to focus on the edited text as the edition's main goal, recent tendencies seem to be less exclusively teleological". Estas

\footnotetext{
${ }^{2}$ Accesible desde https://www.ub.uni-frankfurt.de/archive/schopenhauer_en.html.
} 
tendencias vienen apoyadas por al aumento de las ediciones documentales que las nuevas tecnologías digitales posibilitan y que, frente a la acusación de su reducido carácter crítico, van ganando prestigio y demostrando su utilidad (Pierazzo, 2014).

Se encuentran pocos ejemplos de edición de marginalia, pues la complejidad de su preparación plantea todo un reto, también para los nuevos avances digitales, sobre todo por depender directamente del contexto donde aparecen, a saber, la materialidad del libro. Los archivos e imágenes digitales, aunque han ayudado a localizarlas, se quedan cortas por la falta de intervención editora que las contextualice. No es cierto que el uso de imágenes digitales haga prescindible editarlas: una edición documental puede servir de guía que facilite su lectura e interpretación (Pierazzo, 2014).

Algunos grandes proyectos institucionales volcados en el universo creativo de un autor han comenzado a documentar con estándares digitales las marcas autógrafas en las bibliotecas. El ambicioso proyecto Samuel Beckett. Digital Manuscript Project ${ }^{3}$, reúne primariamente manuscritos, transcripciones y herramientas digitales para facilitar su investigación con la metodología de la crítica genética, pero da un paso más al ofrecer imágenes digitales de los libros de Becket, a los que solo recientemente se ha tenido acceso. Marcas y notas se localizan según el ejemplar y los números de página correspondientes de forma exhaustiva; en algunos casos, se han transcrito selectivamente algunos pasajes marcados. El proyecto ofrece una oportunidad única de conocer cómo Becket, que se calificaba a sí mismo de phrase-hunting, interactuaba con clásicos de la literatura inglesa, francesa e italiana, introduciéndolos en su propia obra y mostrando que era, como Schopenhauer, un gran lector políglota (Van Hulle y Nixon, 2013: XV-XVI).

Melville's Marginalia Online ${ }^{4}$ está dedicado exclusivamente a los libros de Melville, sin formar parte documental de un proyecto de edición más general. Se trata de un archivo virtual, tanto de los libros personales como algunos de los que tomó prestados. En ellos abundan marcas y notas que muestran la intensidad lectora con la que Melville analizaba manuales, por ejemplo, sobre la fisionomía de las ballenas para documentarse para su labor artística. El proyecto ofrece copias digitales acompañadas con las consiguientes descripciones bibliográficas, notas documentales, así como la transcripción de las notas y glosas. No transcribe, sin embargo, el texto base sobre el que se presentan las marcas con lo que es necesario consultar las imágenes digitales, que también se ofrecen de forma paralela junto con las herramientas de búsqueda.

Quisiera, por último, mencionar como ejemplo, el magno proyecto de edición de Walt Whitman, conocido como The Walt Whitman Archive ${ }^{5}$, que en una última fase viene también,

\footnotetext{
${ }^{3}$ Samuel Beckett. Digital Manuscript Project, accesible desde http://www.beckettarchive.org/.

${ }^{4}$ Melville's Marginalia Online, accesible desde http://melvillesmarginalia.org/front.php.

${ }^{5}$ The Walt Whitman Archive, accesible desde http://www.whitmanarchive.org/.
} 
dedicando recursos a la digitalización de las anotaciones y los marginalia del poeta estadounidense. La complejidad de los documentos va más allá de las anotaciones en libros, porque, junto con los clásicos dibujos, subrayados, glosas o marcas, los hábitos de lectura se extienden además a recortes de periódicos, collages, esquemas superpuestos en imágenes, etc., en un complejo legado cultural que complica sobremanera el modulado de su edición digital. A partir de 2016 ya están disponibles algunas transcripciones de notas y marcas en sus libros, que van acompañadas de la transcripción parcial del texto base en la que se presentan 6 .

Estos grandes proyectos académicos ejemplifican que el análisis (interpretación), el etiquetado digital (codificación) y la edición (difusión) de marginalia están comenzando a formar parte de las contribuciones de la crítica textual, de las teorías sobre los procesos de lectura y de la discusión sobre los procedimientos más adecuados para su tratamiento digital.

\section{CLASIFICACIÓN DE LAS ANOTACIONES}

Para proceder a un etiquetado de las anotaciones se debe establecer una diferenciación tipológica. Algunos estudios de genética textual interesados en la relación de los marginalia con el proceso de creación artística han propuesto sistematizar los procesos de interacción partiendo del modo en que los autores trabajan sobre el texto. Según su manera de tomar notas, podemos decir que existen dos tipos de escritores, uno que la crítica ha llamado en inglés extractors, frente a marginalists (Ferrer, 2004: 7-8). Por un lado, están quienes entresacan de entre lo leído fragmentos para guardarlos descontextualizados en libros de notas o en páginas en blanco, y por otro, quienes mantienen la integridad textual de lo leído completándola con sus propias anotaciones: recolectores frente a anotadores, por usar una clasificación terminológica en castellano. Por supuesto en un mismo autor, pueden confluir las dos variantes. Tanto en su periodo estudiantil como en su etapa creativa, Schopenhauer ordenó sus lecturas, reflexiones y estudios en los llamados Notizbücher, cuadernos de notas a los que asignaba distintos nombres: Cogitata, Pandectae, Spicilegia, Senilia, Foliant, Cholerabuch, Adversaria, y en los que recogía los borradores de sus obras junto a referencias o catálogos de citas de lo leído, ya fuera de literatura como de filosofía. La edición y clasificación en nuestro caso tiene que ver, por tanto, con las anotaciones en sus libros y no con sus cuadernos.

6 Un proyecto similar, pero con una perspectiva distinta es Annotated Books Online, http://www.annotatedbooksonline.com/, que presenta como objetivo estudiar los tipos de lectura en la Edad Moderna europea. Incluye herramientas colaborativas para transcribir y traducir directamente sobre las imágenes digitales de los libros. 
Aunque fuera posible proponer una clasificación general aplicable a todo tipo de anotación, las costumbres de cada autor marcan, en el fondo, la pauta. Un primer paso se puede dar, clasificando las marcas estrictamente formales (imprescindible para una codificación posterior) en las que la intervención interpretativa del editor es mínima: marcas verticales, subrayados, correcciones, dibujos, garabatos, etc. A medida que profundizamos en la clasificación la necesidad de interpretación aumenta.

Sobre el glosario español-alemán del apéndice del ejemplar de Las Donquixotadas mas extrañas oder die abenteuerlichsten Ritterthaten des sinnreichen edlen Don Quixote von la Mancha (Emmert, 1826) -una versión reducida del Quijote publicada en Alemania expresamente para facilitar el aprendizaje de la lengua- se observan marcas de estudio que corrigen incluso algunas entradas. El ejemplar del Oráculo manual (del que hablaré más adelante) contiene varios números en los márgenes, de los que es fácil deducir por el contexto que se trata de referencias cruzadas al número de página en el mismo ejemplar; por otro lado, las glosas van desde notas eruditas hasta opiniones que muestran con claridad, acuerdo o desacuerdo con el texto.

Cuando se trata de anotaciones no verbales resulta arriesgado aventurar una interpretación (e incluso la proveniencia), pero un conocimiento profundo de la obra o la biografía del autor puede ofrecernos algún dato relevante. En el ejemplar de la obra teatral de Moratín, El Café o La comedia nueva, Schopenhauer no introduce ninguna marca verbal, solo unas pocas marcas verticales en lápiz sobre algunos parlamentos. El contexto de aparición se refiere a la fama, el mérito, la reforma del teatro y la descripción del carácter de don Pedro, personaje de la obra que representa el buen gusto ilustrado y que critica a los autores noveles de comedias, por su arrogancia ante el supuesto mérito de sus obras y por rechazar los modelos a imitar, el estudio y el verdadero talento. Aunque el mismo Schopenhauer suscribiría, sin duda, la crítica mordaz a los malos poetas, las marcas están en relación directa con el carácter de don Pedro, descrito como una persona solitaria, crítica y de difícil trato, quien, sin embargo, rechaza con justificaciones entrañables la interpretación negativa que el interlocutor hace de su carácter. La biografía del filósofo recoge en numerosas ocasiones cómo su carácter huraño, malhumorado y directo provocaba airadas reacciones en las tertulias y no pocos problemas en su vida privada: don Pedro es un espejo literario donde Schopenhauer cree ver reflejada su propia personalidad. Las marcas muestran su preocupación sobre la opinión de los demás, dejan entrever su opinión sobre su propio carácter, y ofrecen, quizá, una ventana al mismo corazón del filósofo (Losada Palenzuela, 2011: 98-100). Es una de las características de las anotaciones personales su carácter resuelto, íntimo, privado, como reconoce Edgar Allan Poe, también ávido recolector y anotador: "In the marginalia, too, we talk only to ourselves; we therefore talk freshly —boldly originally —with abandonment without conceit" (Harrison, 1965: 2). 
Nuestra codificación se limita por ahora a recoger la clasificación formal, tomando en consideración de entre todas las variantes que identifican, por ejemplo, estudio, resumen, indexación, confrontación, identificación, traducción, polémica, etc., solo las que necesitan de un grado mínimo de interpretación. Las notas del editor pueden completar, dado el caso, la clasificación formal. Buscamos, en definitiva, recoger de manera ordenada los pasajes marcados para ofrecerlos también a la especulación de estudiosos interesados en los aspectos filosóficos, traductológicos, literarios, incluso biográficos de Arthur Schopenhauer.

\section{ETIQUETADO}

Las ediciones críticas digitales actuales se basan en tecnologías relacionadas con el lenguaje estándar de marcado extensible XML, que anotan el texto con elementos que describen sus propiedades, variaciones y estructuras, de manera que pueden ser procesadas automáticamente y descriptivamente tanto su estructura lógica o formal como la información interpretativa que se añade a la edición (Sahle, 2013; Apollon y Belisle, 2014; Pierazzo, 2015). El Consorcio de la Text Encoding Initiative (TEI) lleva proponiendo durante varias décadas criterios de codificación estandarizados conocidos en inglés como Guidelines for Electronic Text Encoding and Interchange ${ }^{7}$ con un amplio número de elementos usados específicamente en las Humanidades en general y las ediciones digitales en particular para el tratamiento de textos en formato digital.

El uso extendido de XML-TEl se conoce, pero me permito recordarlo porque existen ediciones digitales que no usan XML o si lo usan, no siguen necesariamente el estándar del TEI, que a veces también modifican o completan según la propia necesidad editorial. Entre los proyectos de marginalia mencionados anteriormente, solo el Whitman Archive y el Samuel Beckett. Digital Manuscript Project documentan el uso de TEl.

Que el elemento <marginalia> no figure en el estándar de TEI no significa que sea necesario crearlo (el lenguaje XML y por extensión los criterios de la TEl permiten, en cualquier caso, crear y documentar elementos propios). Entre los veintiún módulos que agrupan, de una manera temática, todos los elementos y atributos propuestos, se encuentran repartidas especificaciones que pueden ser útiles para este tipo de manifestación textual: citas, añadidos, sustituciones, supresiones, resaltados, decoración, etc., pueden ser perfectamente codificadas en TEI. En nuestro caso es necesario, además, tener en cuenta con qué textos o, dicho en la terminología del Textrad o del modelo (rueda) textual de Sahle (2013: 46), con qué tipo de contenido, de obra, de lengua, de versión, de documento, de caracteres interactúan las marcas, pues algunas de estas características (libros impresos,

\footnotetext{
${ }^{7}$ TEI Consortium. P5: Guidelines for Electronic Text Encoding and Interchange. Version 3.0.0. Accesible desde http://www.tei-c.org/release/doc/tei-p5-doc/en/html. Citaremos en adelante las Guidelines como TEI, P5: 3.0.0.
} 
prosa, teatro, glosarios, traducciones, aforismos) deben ser incluidos con sus particularidades en el etiquetado.

En el caso de la biblioteca de Schopenhauer se etiqueta el registro de los libros, como se viene haciendo de forma estándar, en un encabezamiento TEI: <teiHeader>. Toda la información relativa al impreso (procedencia, repositorio, signatura de la biblioteca, identificador digital único, etc.) se codificará como libro usando el elemento <sourceDesc>, que incluye <biblFull> para una descripción bibliográfica completa. Para la descripción explicativa de las marcas manuscritas dentro del encabezamiento se usa el elemento <additions>, que como explican las Guidelines, "contains a description of any significant additions found within a manuscript, such as marginalia or other annotations" (TEI, P5: 3.0.0).

Al tratarse, en el caso de la biblioteca española de Schopenhauer, de impresos del $\mathrm{XVI-XVIII} \mathrm{en} \mathrm{los} \mathrm{que} \mathrm{concurren} \mathrm{las} \mathrm{características} \mathrm{propias} \mathrm{de} \mathrm{la} \mathrm{época} \mathrm{se} \mathrm{prefiere} \mathrm{mantener}$ una edición semidiplomática, pues las posibles variantes modernas del texto base pueden hacer perder el sentido a la interpretación de las marcas. Por ejemplo, la tradición impresa del Oráculo manual y arte de prudencia, modificó la disposición tipográfica de los aforismos. La edición príncipe y las primeras ediciones españolas no incluyeron ningún tipo de diferenciación que tipográficamente destacara las máximas o numerara los aforismos (el libro es un conjunto de 300 aforismos encabezados normalmente con una frase o sentencia breve que hace las veces de máxima), fue a partir del gran éxito de la traducción francesa, que impulsó la difusión. Cuando se adopta este criterio tipográfico que facilita una lectura en forma lineal, aunque no fuera necesariamente la intención de Gracián, quien ofrece el libro para una lectura en forma de una moderna rayuela donde el lector debe crear su propio camino y establecer su propia red de correspondencias semánticas (Blanco, 1997: 63-64). Muchos de los números al margen y las frases subrayadas por Schopenhauer están relacionadas directamente con la ausencia de disposición tipográfica, pues representan su propia guía de lectura en la búsqueda de referencias temáticas cruzadas en el texto o interpretan qué parte del aforismo corresponde a la máxima. Este ejemplar sirvió para la traducción al alemán, por lo que también incluye correcciones o puntuación que ponen orden, en la de por sí caótica, disposición ortotipográfica del original, que toda edición crítica moderna, en cualquier caso, modifica. En la descripción de la codificación, <encodingDesc>, se incluye, por tanto, la explicación sobre el grado de normalización, <normalization>, que se lleva a cabo sobre el texto soporte de las marcas. De igual manera, por ejemplo, se explica en <hyphenation> el criterio seguido con los guiones de separación de palabras en el original. Aunque puedan ser en principio de una importancia menor, la disposición de los saltos de línea en el original, nos permite reconstruir desde dónde y hasta dónde se añade, por ejemplo, una marca lateral. Mencionaré más adelante, la necesidad de codificar los saltos de línea para poder recuperar el texto que selecciona una marca, pero en este proyecto el criterio de la profundidad del 
marcado (granularity) se limita a los elementos básicos del texto y siempre que tengan una relación directa con las marcas o sirvan para documentarlas.

Un último elemento específico dentro del encabezamiento TEI es el dedicado a las manos en el impreso. Con el elemento <handNotes> y el subelemento <handNote> se recogen, no solo la descripción de la proveniencia de las marcas, sino que también se especifican, con la ayuda de atributos como @scribe, @script, @medium, @scope, las marcas hechas con tinta o con lápiz, que pueden también identificar distintas fases de lectura, que luego gracias a un identificador único, @xml:id, pueden ser relacionadas con la codificación de la marca dentro del texto.

La codificación de las marcas en sí se incorpora en la codificación general que se recoge dentro del elemento <text>. El texto base impreso se transcribe en su totalidad o en parte dependiendo de la densidad de la anotación. Todas las marcas o anotaciones añadidas al texto impreso se reúnen en el elemento <add> que "contains letters, words, or phrases inserted in the source text by an author, scribe, or a previous annotator or corrector" (TEI, P5: 3.0.0) completándolo con una selección de atributos @type y @subtype que permiten cubrir toda la variación tipológica, cuyos valores, pueden ser, por ejemplo: @type: Unterstreichung I Randstreichung | Glosse | Gekritzel | Korrektur; @subtype: simple | double | triple | union | doodle | index | archive.

Más adelante explicaré algunas de las posibles desviaciones de esta elección frente a los criterios del TEl. En cualquier caso, creo ganar de esta manera cierta consistencia al agrupar en un solo elemento toda marca, glosa, nota o subrayado ajenos al impreso original. A modo de ejemplo podemos presentar las siguientes variantes:

<add type="Glosse" subtype="index"> Referencia cruzada a un número de página. <add type="Glosse" subtype="statement"> Glosa que opina sobre el texto. <add type="Korrektur" subtype="union"> Corrección del original que une dos palabras <add type="Korrektur" subtype="punctuation"> Modificación de la puntuación del original

<add type="Randstreichung" subtype="triple"> Marca (línea) lateral repetida tres veces.

<add type="Unterstreichung"> Subrayado

Anotaciones, subrayados y correcciones descritos por el elemento <add> se añaden así al etiquetado básico del libro. Además de @type y @subtype, el elemento <add> se completa con los atributos @hand, @place, @medium, para indicar el tipo de mano, el lugar de la marca o el medio (tinta o lápiz). 
Las marcas laterales verticales, a derecha o izquierda de la página, usan como punto de referencia las líneas en las que está dividido el texto impreso en la caja. Se etiquetan, por tanto, también los comienzos de línea con el elemento $\langle\mid b\rangle$ : el elemento <add $\rangle$ que describe una marca lateral (type="Randstreichung") comienza y termina siempre entre dos comienzos de línea. De esta manera es posible recuperar el texto que se marca de línea a línea, teniendo incluso en cuenta si el comienzo de línea $\langle\mathrm{lb}\rangle$ divide una palabra (break="no") o si esta tiene un guión (type="guion"). Para el caso de que las anotaciones sean, por ejemplo, una referencia cruzada al número de página en el original se codifican los saltos de página con $<\mathrm{pb}>$ con su correspondiente @xml:id de manera que puedan ser enlazadas con el atributo @target.

En el caso de la codificación del Oráculo manual, que estamos citando como ejemplo, aunque no están presentes en el texto impreso original y por tanto implican un grado mayor de interpretación del editor, se codifican, asimismo, las máximas de cada aforismo con <seg>, un atributo @type y un @xml:id, pues están relacionadas directamente con el tipo de anotación de Schopenhauer; por otro lado, facilitan una posterior visualización. Las glosas que se dejen interpretar en su relación con una marca o un fragmento del texto se referencian con el atributo @target dentro del elemento <add>.

El uso del elemento <add> para cualquier glosa, número o frase añadidos al texto impreso sigue literalmente la recomendación de las Guidelines. No obstante, contra la elección de <add type="Unterstreichung"> para un subrayado, se podría argüir que no se codifica en propiedad un fragmento de texto, una palabra o una frase añadidos, sino únicamente una línea horizontal; de hecho, el texto que se recoge entre la apertura y el cierre de <add> pertenece al texto impreso bajo el que se añade el subrayado. Tanto en la codificación de manuscritos como en la de impresos es un criterio común servirse del elemento < hi> (highlight) completado con el atributo @rend, que puede especificar cualquier tipo de visualización. Reconozco que sin ningún inconveniente podría elegirse para este modelo, sin embargo, esto no significa que <hi> carezca totalmente de ambigüedad. Habitualmente el elemento $<$ hi $>$ se usa en los impresos para marcar elementos tipográficos (cursivas, negritas, etc.) que ya se encuentran en el original, mientras que la elección de $<$ add> permite agrupar todas las marcas externas y añadidas a un impreso, por lo general hechas en el curso de una lectura de un libro.

Una segunda objeción podría basarse en una de las críticas de base al XML como modelo de documentación de textos, a saber, el solapamiento (overlap) (Schmidt, 2010: 343344). Al no ser <add> un elemento vacío, existe la posibilidad de que las líneas verticales laterales o glosas, que por su propia naturaleza en el espacio de la hoja se podrían imbricar sobre otros elementos del texto, no puedan ser etiquetadas. Tras un primer repaso tipológico de las marcas en nuestro corpus teniendo en cuenta la posible codificación del texto base, no 
se han encontrado estos problemas. Ya he comentado cómo la codificación del texto base es ciertamente mínima, pero incluso allí donde, por ejemplo, se codifican los comienzos de línea no se presenta el problema, entre otras razones porque el elemento $<|b /\rangle$ es un elemento vacío. Incluso en el caso en que una glosa se encuentre, por ejemplo, dentro de una marca lateral o un subrayado, se puede aplicar el elemento <add>, pues la recomendación de las Guidelines permite la inclusión de <add> dentro de sí mismo. Tampoco resolverían el solapamiento desde este punto de vista otras posibles propuestas para codificar notas al margen, por ejemplo, con el elemento <note> junto con el atributo @resp (con un valor que indique un autor frente a un editor) o con el elemento <gloss> (las Guidelines ejemplifican su uso, sobre todo, con aclaraciones dentro del texto mismo).

Existen otras soluciones de codificación para este tipo de manifestación textual. El propio elemento <add> presenta una variante en el elemento vacío <addSpan/>. Con <addSpan/> se marcaría el comienzo de la anotación manuscrita. El atributo que lleva asociado, @spanTo, enlazaría con su correspondiente @xml:id en el elemento <anchor/>, que marcaría el final de la anotación. Los dos elementos vacíos permiten así sortear cualquier problema de solapamiento. Para subrayados o marcas laterales que no puedan ser transcritos con < hi> se puede asimismo aplicar un simple <span/> con los atributos @from @to enlazados con un <anchor/> por medio de un @xml:id. Para tachaduras o supresiones de cualquier tipo existe asimismo el correspondiente <delSpan>.

La consistencia en la elección de elementos se resiente, pues queda claro que en estos casos para una misma manifestación textual dentro del mismo documento tendríamos que elegir distintos elementos para sortear, por ejemplo, los problemas de imbricación.

La justificación de nuestra elección se basa, en parte, en una mayor claridad para una codificación directa apoyada en editores XML (tipo oXygen, en modo texto), menos automatizada que otros entornos de transcripción más complejos. Siempre que no se presente un problema evidente de consistencia o solapamiento, la documentación puede dejar claro qué tipo de criterios editoriales y de codificación se siguen y en qué medida se cumplen las recomendaciones del TEI.

Otra razón que se puede alegar es el menor grado de complejidad que supone este etiquetado frente al que se basa en elementos vacíos cuando transformamos el documento XML usando las hojas de estilo XSLT. Pondré algunos ejemplos en el siguiente apartado dedicado a la publicación digital usando el entorno de publicación de Drupal.

\section{PUBLICACIÓN DIGITAL}


El entorno de publicación elegido utiliza Drupal, un sistema modular de gestión de contenidos (CMS), implementado con el módulo $\mathrm{TEICHI}^{8}$, que, dentro de la estructura clásica de PHP y SQL, permite publicar, visualizar e interactuar con ficheros XML-TEI, gracias a XSLT, CSS y JavaScript.

La necesidad de herramientas que faciliten, a editores menos experimentados técnicamente, ofrecer en línea sus trabajos, es un asunto tratado recurrentemente en el ámbito de las Humanidades Digitales y del estándar TEI, en particular (Flanders y Hamlin: 2013). El módulo de TEICHI para Drupal se ofrece en este sentido como un framework para publicación de ediciones digitales que ayuda a superar las barreras entre un texto ya etiquetado y la publicación en línea (Pape et al.: 2012).

Uno de los argumentos básicos que se aduce en el uso de este lenguaje, reside en su enorme potencial para representar una estructura de datos independientemente de su ulterior visualización. La complejidad técnica se convierte, sin embargo, en una barrera difícil de superar, cuando entran en juego los condicionantes necesarios para su publicación, tratamiento o preservación. Es un hecho que proyectos de edición complejos terminan creando sus propias herramientas o adaptando las existentes a la medida de las propias necesidades, no solo para la publicación, sino para controlar todos los pasos ya desde el mismo etiquetado. Aunque la ventaja de la separación entre estructura y visualización es indiscutible, no es menos cierto, como apunta Pierazzo, que toda edición digital necesita tener en cuenta, incluso antes de la selección del etiquetado, cómo va a ser su visualización o qué uso se quiere dar a la información que se está modelando: "determining what a digital edition should do will determine the theoretical model that should lie at its base" (Pierazzo, 2015: 117).

El módulo TEICHI ofrece una amplia paleta de opciones que facilitan, a través de las interfaces gráficas de usuario (GUI) nativas de Drupal, como desde las del propio módulo: subir archivos XML-TEI, descargarlos en varios formatos (TXT, EPUB, XML), navegar por distintas visualizaciones, mostrar variaciones textuales, organizar capítulos en forma de libro (usando el módulo book de Drupal), incluir imágenes digitales, etc. ${ }^{9}$, todo ello sin necesidad de ver una línea de código.

El documento debe estar ya disponible en TEI, pues el módulo TEICHI no está pensado para la codificación sino solo para la publicación. La utilidad del módulo se limita, sin embargo, al subconjunto de elementos, TEI Lite. Esta personalización TEI Lite está pensada para una modulación básica que, a pesar de que podría cubrir un noventa por ciento de las necesidades editoriales (Burnard y Sperberg-McQueen, 2012), existen casos en los que no es aplicable (Burghart y Rehbein: 2012).

\footnotetext{
${ }^{8}$ The TEICHI Framework. Bringing TEI Lite to Drupal. Accesible desde http://www.teichi.org/.

${ }^{9}$ Véanse las TEICHI Features, accesibles desde http://www.teichi.org/features.
} 
El equilibrio de los entornos de publicación entre la generalidad y la especificidad de cada proyecto es, por tanto, difícil de alcanzar. La elección de un elemento o atributos específicos convierte su diseño en algo complejo, pero considero que la dificultad es doble: no solo reside en el etiquetado, sino en cómo éste necesita ser tratado. El módulo TEICHI facilita la visualización gracias a la inclusión, por defecto, de una hoja de estilo XSLT, que realiza la transformación del documento XML-TEI (Lite) en HTML, combinándolo con CSS para su diseño y con JavaScript para su interacción. La hoja de estilo XSLT del módulo incluye la regla (template) necesaria para procesar el elemento <add>:

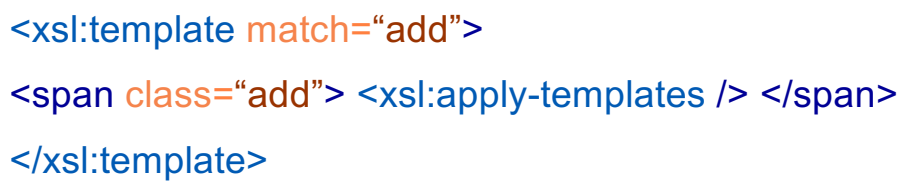

El elemento <add >, fundamental en nuestro marcado, está presente en el subconjunto de TEI Lite, pero nuestra propia lista de valores para los atributos @type y @subtype hace que la regla (template) no cubra nuestras necesidades, que pueden ir desde la mera visualización hasta una categorización específica basada, por ejemplo, en un diseño de colores para las manos o para el medio (tinta o lápiz). Para procesar, por ejemplo, la línea de código XML:

<add type="Randstreichung" subtype="triple" hand="\#SchopPencil">mal. Que ay muchos monstruos en $<\mid \mathrm{b} />$ el estendido pais de la impertinen $<\mid \mathrm{b}$ type="hyphen InWord" break="no"/>cia. $</$ add $>$,

necesitamos usar una regla (template) que tenga en cuenta los atributos:



Por otro lado, como comentaba más arriba, la elección de un modelo de etiquetado condiciona también el nivel de dificultad que tenemos que afrontar cuando se programan las 
hojas de estilo XSLT. Decidirse por <add> con los atributos @type y @subtype supone reducir asimismo la complejidad de las reglas necesarias para recuperar la información. Mientras que con una (simple) regla como:

<xsl:for-each select=“add[@type = 'Randstreichung']">,

se pueden recuperar, por ejemplo, todas las marcas verticales. El uso de elementos vacíos <addSpan/> (no presente en TEI Lite), <span/>, <anchor/> obliga a cierto malabarismo con el XPath, como muestra este ejemplo:

\section{<xsl:template \\ match="text()[preceding::addSpan[1]/@spanTo=following::anchor[1]/@xml:id]">}

La multiplicación de factores que determinan todo proceso de edición digital, desde su modulación hasta su publicación, puede llegar a ser abrumadora, por eso cualquier decisión consciente que permita reducirlos, más si cabe para proyectos menores o para editores menos expertos, debe ser tomada en cuenta.

Aunque ni las hojas de estilo (XSLT, CSS) ni el código JavaScript que el módulo TEICHI ofrece por defecto nos sirven, sí podemos usar indirectamente la capacidad de publicar contenido en XML que el módulo provee. Desde luego infrautilizamos sus recursos, pero nos evitamos tener que crear todo un framework de publicación reutilizando, en parte, algunas de sus funcionalidades.

Una instalación estándar de Drupal limita a tres, los formatos para publicar distintos tipos de contenido (text formats): filtered HTML, full HTML y plain text ${ }^{10}$. Estos tipos de contenido pueden ser seleccionados $y$, en parte, configurados a través de la interfaz de usuario de Drupal. Una vez instalado el módulo TEICHI, a estos tres formatos, se añade otro tipo de text format que permite usar código XML-TEI como tipo de contenido. El módulo activa la librería libxslt que permite procesar XSLT en $\mathrm{PHP}^{11}$ e indica cuáles son los archivos por defecto (XSLT, CSS o JavaScript) que debe usar para el procesamiento del TEI. Para nosotros la ventaja reside en que se ofrece, asimismo, la posibilidad a través de la GUI de sustituir las hojas de estilo por defecto permitiendo al procesador XSLT usar las propias.

El módulo, en definitiva, añade a la configuración de los text formats de Drupal, la posibilidad de usar XSLT para procesar XML, por lo que podemos crear incluso nuestro tipo de contenido específico sin necesidad de modificar el que ofrece el módulo por defecto.

\section{CONCLUSIONES}

\footnotetext{
${ }^{10}$ Véase la documentación de Drupal, accesible desde http://www.drupal.org/documentation.

${ }^{11}$ Véase la documentación de TEICHI, accesible desde http://www.teichi.org/documentation.
} 
Ha sido la intención de este trabajo abordar algunas de las fases de un proyecto de edición digital, para mostrar que los marginalia pueden ser también objeto de la crítica textual. La mera digitalización en forma de imágenes es, sin duda, una fuente valiosísima de información. Si a aquella añadimos reflexión e interpretación, producimos conocimiento. Este papel lo cumplen las ediciones digitales (críticas o documentales) que buscan establecer, preservar o documentar un texto basándose en premisas científicas (Price, 2008). Se ha justificado, asimismo, el uso del elemento <add> para etiquetar toda marca externa añadida a un impreso durante un proceso de lectura, no solo con la intención de unificar el etiquetado sino también para facilitar un tratamiento posterior. Para su publicación, se ha propuesto Drupal implementado con el módulo TEICHI. En la elección de este modelo de publicación subyace la necesaria adaptación de todo proyecto digital, entre otros factores, a los recursos y las capacidades disponibles a sus editores (Pierazzo, 2015: 117-118).

\section{REFERENCIAS BIBLIOGRÁFICAS}

APOLLON, D. y BELISLE, C. (2014). Digital Critical Editions. Urbana-Springfield-Chicago: University of Illinois Press.

BLANCO, E. (1997). "Introducción”. En Baltasar Gracián. Oráculo manual y arte de prudencia, E. Blanco (ed.), 15-73. Madrid: Cátedra.

BURGHART, M. y REHBEIN, M. (2012). "The Present and Future of the TEl Community for Manuscript Encoding". Journal of the Text Encoding Initiative, 2. Recuperado de http://jtei.revues.org/372 el 01/03/2017.

BURNARD, L. y SPERBERG-MCQUEEN, C.M. (2012). TEI Lite: Encoding for Interchange: an Introduction to the TEI. Final Revised Edition for TEI P5. Recuperado de http://www.teic.org/release/doc/tei-p5-exemplars/html/tei lite.doc.html el 01/03/2017.

EMMERT, J.H. (1826). Las Donquixotadas mas extrañas. Oder die abenteuerlichsten Ritterthaten des sinnreichen edlen Don Quixote von la Mancha. Tübingen: Osiander.

FERRER, D. (2004). "Towards a Marginalist Economy of Textual Genesis". En Variants. Reading Notes, D. Van Hulle y W. Van Mierlo (eds.), 2-3, 7-18. Amsterdam-New York: Rodopi.

FLANDERS, J. y HAMLIN, S. (2013). "TAPAS: Building a TEI Publishing and Repository Service". Journal of the Text Encoding Initiative, 5. Recuperado de http://jtei.revues.org/788 el 01/03/2017.

GRACIÁN, B. (1647). Oráculo manual y arte de prudencia. Huesca: Juan Nogués. 
HARRISON, J. (ed.) (1965). The Complete Works of Edgar Allan Poe. Volumen XVI. Marginalia-Eureka. General Index. New York: AMS Press Inc.

HÖLTER, A. (2011). "Tiecks Bibliothek". En Ludwig Tieck. Leben, Werk, Wirkung, C. Stockinger y S. Scherer (eds.), 314-321. Berlín-New York: De Gruyter.

HÜBSCHER, A. (ed.) (1968). Der handschriftliche Nachlaß, I-V. Frankfurt am Main: Waldemar Kramer.

HULLE, D. Van y MIERLO, W. Van (2004). "Reading Notes: Introduction". En Variants. Reading Notes, D. Van Hulle y W. Van Mierlo (eds.), 2-6. Amsterdam-New York: Rodopi.

HULLE, D. Van y NIXON, M. (2013). Samuel Beckett's Library. Cambridge: Cambridge University Press.

JACKSON, H.J. (2001). Marginalia: Readers Writing in Books. New Haven: Yale University Press.

(2005). Romantic Readers. The Evidence of Marginalia. New Haven: Yale University Press.

LOSADA PALENZUELA, J.L. (2011). Schopenhauer traductor de Gracián. Diálogo y formación. Valladolid: Servicio de Publicaciones de la Universidad de Valladolid.

PAPE, S., SCHÖCH, C. y WEGNER, L. (2012). "TEICHI and the Tools Paradox. Developing a Publishing Framework for Digital Editions". Journal of the Text Encoding Initiative, 2. Recuperado de http://jtei.revues.org/432 el 01/03/2017.

PIERAZZO, E. (2014). "Digital Documentary Editions and the Others". Scholarly Editing: The Annual of the Association for Documentary Editing, 35. Recuperado de http://www.scholarlyediting.org/2014/essays/essay.pierazzo.html el 01/03/2017. (2015). Digital Scholarly Editing: Theories, Models and Methods. Farnham-Burlington: Ashgate Publishing.

PRICE, K.M. (2008). "Electronic Scholarly Editions". En A Companion to Digital Literary Studies, S. Schreibman y R. Siemens (eds.). Oxford: Blackwell. Recuperado de http://www.digitalhumanities.org/companionDLS el 01/03/2017.

SAHLE, P. (2013). Digitale Editionsformen. Zum Umgang mit der Überlieferung unter den Bedingungen des Medienwandels. Teil 3: Textbegriffe und Recodierung, 9. Norderstedt: Schriften des Instituts für Dokumentologie und Editorik, Books on Demand (BoD).

SCHMIDT, D. (2010). “The Inadequacy of Embedded Markup for Cultural Heritage Texts”. En Literary and Linguistic Computing, 25.3, 337-356. Oxford: Oxford University Press.

TEI Consortium. P5: Guidelines for Electronic Text Encoding and Interchange, versión 3.0.0. Recuperado de http://www.tei-c.org/release/doc/tei-p5-doc/en/html el 01/03/2017. 